Centre interuniversitaire de recherche

en économie quantitative

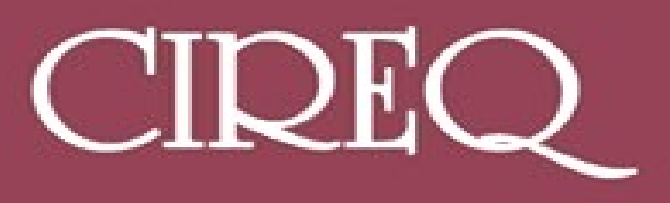

Cahier 02-2012

Prices of Durable Nonrenewable Natural Resources under Stochastic Investment Opportunities

Calvin AtewAmba and Gérard GAUDET 


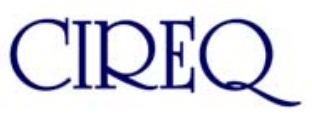

Le Centre interuniversitaire de recherche en économie quantitative (CIREQ) regroupe des chercheurs dans les domaines de l'économétrie, la théorie de la décision, la macroéconomie et les marchés financiers, la microéconomie appliquée et l'économie expérimentale ainsi que l'économie de l'environnement et des ressources naturelles. Ils proviennent principalement des universités de Montréal, McGill et Concordia. Le CIREQ offre un milieu dynamique de recherche en économie quantitative grâce au grand nombre d'activités qu'il organise (séminaires, ateliers, colloques) et de collaborateurs qu'il reçoit chaque année.

The Center for Interuniversity Research in Quantitative Economics (CIREQ) regroups researchers in the fields of econometrics, decision theory, macroeconomics and financial markets, applied microeconomics and experimental economics, and environmental and natural resources economics. They come mainly from the Université de Montréal, McGill University and Concordia University. CIREQ offers a dynamic environment of research in quantitative economics thanks to the large number of activities that it organizes (seminars, workshops, conferences) and to the visitors it receives every year.

\title{
Cahier 02-2012
}

\section{Prices of Durable Nonrenewable Natural Resources under Stochastic Investment Opportunities}

\author{
Calvin AteWAmBA and Gérard GAUDET
}

CIREQ, Université de Montréal C.P. 6128, succursale Centre-ville Montréal (Québec) H3C 3J7 Canada cireq@umontreal.ca http://www.cireq.umontreal.ca
Universite th de Montréal
McGill

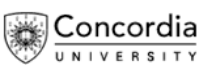


Ce cahier a également été publié par le Département de sciences économiques de l'Université de Montréal sous le numéro (2012-01).

This working paper was also published by the Department of Economics of the University of Montreal under number (2012-01).

Dépôt légal - Bibliothèque nationale du Canada, 2012, ISSN 0821-4441

Dépôt légal - Bibliothèque et Archives nationales du Québec, 2012

ISBN-13 : 978-2-89382-625-7 


\title{
Prices of Durable Nonrenewable Natural Resources under Stochastic Investment Opportunities]
}

\author{
Calvin Atewamba and Gérard Gaudet \\ Département de sciences économiques and CIREQ \\ Université de Montréal
}

November 2011

\footnotetext{
${ }^{1}$ Please address correspondence to: Département de sciences économiques, Université de Montréal, C.P. 6128, Succ. Centre-Ville, Montréal, Québec H3C 3J7, Canada.
} 


\begin{abstract}
We take a capital asset pricing approach to the determination of the price of a nonrenewable natural resource in the case where the resource is durable, in the sense that once extracted it becomes a productive asset held above ground. The portfolio choice is then made up of the following assets: a stock of nonrenewable resource held in the ground that yields no dividend, a stock of resources held above ground that yields a dividend in the form of a flow of productive services, and a stock of composite good that can be held either in the form of productive capital or of a bond whose return is given. There is a stochastic element to the rate of change of productivity in both the production of the composite good and in the extraction of the resource. It is shown that the resulting prediction for the price path of the resource differs considerably from the one that follows from the elementary Hotelling model and that no unambiguous prediction can be drawn analytically about the pattern of behavior of that price path.
\end{abstract}

\title{
Résumé
}

On étudie l'évolution du prix d'une ressource naturelle non renouvelable dans le cas où cette ressource est durable, c'est-à-dire qu'une fois extraite elle devient un actif productif détenu hors terre. On emprunte à la théorie de la détermination du prix des actifs pour ce faire. Le choix de portefeuille porte alors sur les actifs suivant : un stock de ressource non renouvelable détenu en terre, qui ne procure aucun service productif; un stock de ressource détenu hors terre, qui procure un flux de services productifs; un stock d'un bien composite, qui peut être détenu soit sous forme de capital productif, soit sous forme d'une obligation dont le rendement est donné. Les productivités du secteur de production du bien composite et du secteur de l'extraction de la ressource évoluent de façon stochastique. On montre que la prédiction que l'on peut tirer quant au sentier de prix de la ressource diffère considérablement de celle qui découle de la règle d'Hotelling élémentaire et qu'aucune prédiction non ambiguë quant au comportement du sentier de prix ne peut être obtenue de façon analytique. 


\section{Introduction}

The basic Hotelling model of the exploitation of a nonrenewable natural resource Hotelling, 1931) predicts that the in situ price of the resource (its flow price minus the marginal cost of extracting it, often called the Hotelling rent) will, in equilibrium, grow at the rate of interest. This means that the rate of growth of the flow price will be a weighted average of the rate of interest and the rate of change of the cost of extraction, with the weights being respectively the share of rent and of cost in the price. Therefore, although the price may at first decline if the cost of extraction is decreasing, it must eventually follow an increasing path since the share of rent in the price is increasing with time and that of cost is decreasing. This basic model, known as the Hotelling rule, has been the source of much theoretical insights into the behavior of natural resource markets. There is however very little evidence that resource prices do indeed behave as predicted $!^{1}$ This should not be too surprising, since this parsimonious basic model neglects a number of important factors which will also play a role in determining the real world behavior of resource prices. ${ }^{2}$ Among those factors are uncertainty about future prospects and the fact that many nonrenewable natural resources are durable, contrary to what is most often assumed in theoretical modeling. The purpose of this paper is to explore the impact on the equilibrium pricing of natural resources of simultaneously taking into account those two factors.

There is an extensive literature on the presence of uncertainty in various forms in natural resource markets ${ }^{3}$ This paper follows closely the modeling of stochastic future prospects proposed in Gaudet and Khadr (1991), which studied the case of non durable natural resources. What distinguishes Gaudet and Khadr (1991) from the previous literature is that it takes an intertemporal asset pricing approach to the problem. Thus the Hotelling rule is interpreted as an equilibrium asset pricing condition, the asset being of course the stock of the resource held in the ground. This asset, contrary to a reproducible asset such as conven-

\footnotetext{
${ }^{1}$ See Slade and Thille (2009) and Livernois (2009) for excellent recent surveys of empirical analyses of the Hotelling rule.

2 Gaudet (2007) discusses in more details some of those factors.

${ }^{3}$ See Gaudet and Khadr (1991) and the references cited therein.
} 
tional physical capital, has the particularity that it cannot be increased, with the result that disinvestment decisions are irreversible. The question then becomes: what is the appropriate rate of return on holding a unit of the resource in the ground. In the basic deterministic framework assumed by Hotelling the answer is simply the capital gains that can be obtained from holding it in situ. When investment opportunities are stochastic, it is shown in Gaudet and Khadr (1991) that its equilibrium expected return will depend also on the degree of risk aversion and on how its return happens to be correlated with the performance of the economy in terms of consumption.

Nonrenewable resources most often bring to mind fossil fuels, such as petroleum, natural gas and coal. Although those natural resources are storable, they are not durable, since they are consumed in a single usage. But many nonrenewable resources, such as metals, are durable: once extracted they become above ground assets capable of yielding a continuous flow of services used as input into various production processes. We are then in presence of two resource assets: a stock held below ground that yields no flow of services, and a stock held above ground that does. Those assets have the particularity that the one held above ground can only be increased by depleting the one below ground. Levhari and Pindyck (1981) is the most important reference on the behavior of markets for durable resources, a topic on which there is surprisingly very little literature even though many important nonrenewable resources are in fact durable. It considered the pricing of durable resources in a partial equilibrium context. In this paper we combine an approach similar to that of Levhari and Pindyck (1981) for modeling the durability of the resource with the two-goods multi-assets stochastic pricing framework of Gaudet and Khadr (1991).

The next section will present the model; it follows closely that of Gaudet and Khadr (1991), into which we integrate the durability of the resource à la Levhari-Pindyck. We then characterize in succession the efficient extraction of the resource in Section 3 and, in Section 4, the efficient production of a composite good that uses the services of the above ground stock of the resource as an input and that can be either consumed or accumulated. The efficiency conditions thus derived serve to determine the consumer's opportunity set 
subject to which he makes his consumption and portfolio decisions, solved for in Section 5 . This enables us to characterize in Section 6 the expected equilibrium behavior of both the asset price and the flow price of the resource, and to highlight the effect of durability on the expected price path as compared to non durable resources, as well as to a deterministic context. Brief concluding remarks follow in Section 7 .

\section{The model}

Consider an economy in which there are two goods: a composite good and a durable nonrenewable natural resource. The composite good can be either consumed or accumulated. Its accumulated stock is held either in the form of physical capital, the stock of which at time $t$ is denoted $K(t)$, or in the form of a "bond", the stock of which is $B(t)$. This bond is assumed to reproduce itself at the given exogenous and riskless rate $r$, which will represent the force of interest in the economy $\left.\right|^{4}$ The accumulated stock of capital is used as an input both in the production of the composite good and in the extraction of the nonrenewable resource.

The ultimate stock of the resource available is assumed given and known. The reserves left in the ground at time $t$ will be denoted $X(t)$. Being durable, the resource, once extracted, accumulates above ground in the form of a stock which depreciates at the constant rate $\delta \geq 0$. This durable above ground stock, $Q(t)$, yields a flow of services which enters the production of the composite good along with the services of physical capital. There are therefore four assets in which the wealth of this economy can be held, at any given time: bonds, capital, reserves of the natural resource, and the above ground resource stock. The latter two assets have the particularity that the above ground stock can only be increased by reducing the in ground reserves. The resource being nonrenewable, its reserves cannot be increased and the decision to extract is irreversible. As for the stock of the composite good, it will be assumed costlessly transferable between its three uses. For simplicity, the stock of capital

\footnotetext{
${ }^{4}$ For notational convenience we will treat $r$ as time-invariant. Doing so does not affect our results. It will become clear that it can just as well be thought of as an exogenous time path, which could also be stochastic.
} 
will be assumed not to depreciate.

The production process and the extraction process are both assumed to have a stochastic element. More precisely, if $y(t)$ denotes the production of the composite good and $x(t)$ the extraction of the resource, then:

$$
\begin{gathered}
y(t)=F\left(K_{y}(t), Q(t), \theta_{1}(t)\right) \\
x(t)=G\left(K_{x}(t), \theta_{2}(t)\right),
\end{gathered}
$$

where $K_{y}(t)+K_{x}(t)=K(t)$. The state variables $\theta_{1}(t)$ and $\theta_{2}(t)$ can be viewed as stochastic productivity indices. They will be assumed to evolve exogenously according to the following Itô processes:

$$
\frac{d \theta_{i}(t)}{\theta_{i}(t)}=\mu_{i} d t+\sigma_{i} d Z_{i}(t), \quad i=1,2 ; \quad \forall t,
$$

with $d Z_{i}(t)=\xi_{i} \sqrt{d t}, \xi_{i} \sim N(0,1), \operatorname{cov}\left(d \theta_{1}, d \theta_{2}\right)=\sigma_{12} d t+o(d t)$ and $\sigma_{12}=\sigma_{1} \sigma_{2} \operatorname{cov}\left(\xi_{1}, \xi_{2}\right)$. The drifts $\mu_{i}$ and the variance $\sigma_{i}$ could depend on time $t$ and the state variables.

We will assume $F_{1}>0, F_{1 Q}$ and $F_{1 K}>0$, where the subscript 1 denotes the partial derivative of $F(\cdot)$ with respect to $\theta_{1}$. We will also assume $F_{K}>0, F_{Q}>0, F_{K K}<0$, $F_{Q Q}<0, F_{Q K}>0$, and $\lim _{K \rightarrow 0} F_{K}(K, Q)=\infty, \lim _{Q \rightarrow 0} F_{K}(K, Q)=\infty$. Under those conditions it will take an infinite time to exhaust the reserves.

As for the extraction process, it will be assumed, for simplicity, to be given by:

$$
G\left(K_{x}, \theta_{2}\right)=\frac{K_{x}}{\gamma\left(\theta_{2}\right)}
$$

The function $\gamma\left(\theta_{2}\right)$ tells us how many units of capital is required to extract a unit of the resource. Hence the cost of extraction will be $r \gamma\left(\theta_{2}\right) x(t), r$ being the opportunity cost of capital, and $\gamma\left(\theta_{2}\right) x(t)$ the quantity of capital in use as input. It is assumed that $\gamma^{\prime}\left(\theta_{2}\right)<0$, $\lim _{\theta_{2} \rightarrow 0} \gamma\left(\theta_{2}\right)=\infty$, and $\lim _{\theta_{2} \rightarrow+\infty} \gamma\left(\theta_{2}\right)=0$.

The representative consumer derives utility $U(c(t))$ from consuming the composite good at the rate $c(t)$. This utility function satisfies $U(c)>0, U^{\prime}(c)>0, U^{\prime \prime}(c)<0$, and 
$\lim _{c \rightarrow 0} U^{\prime}(c)=\infty$. The consumer discounts the utility flows at the constant rate $\alpha$.

It will be assumed that all agents in this economy behave as price takers, both in the goods and in the assets markets. Consumers are assumed to be the owners of the assets in the economy. In deciding on their consumption and on their portfolio, they transmit demand prices to the composite good producers and the resource extractors, who take them as given in making their decisions. Their production and extraction decisions then enter the determination of the rates of return on the assets, which the consumers take as given in making their own decisions. These prices and returns are taken to be those that equilibrate the markets when production, extraction and consumption take place simultaneously.

In the next two sections we derive necessary efficiency conditions for the extraction of the resource and for the production of the composite good. These will generate the rates of return on assets that will enter the wealth constraint to the consumer's intertemporal optimization problem.

\section{Efficient resource extraction}

The typical price-taking resource extraction firm chooses its rate of extraction so as to maximize the expected present value of the flow of profits over time. Those profits are measured in monetary units (we will call them "utils") and are discounted at the constant rate $\alpha$. Let $p(t)$ denote the market flow price of a unit of the resource, measured in units of the composite good, and let $q(t)$ denote the demand price (in utils) of the composite good. The extraction firm takes those prices as given in making its extraction decision. We will assume for now that those prices evolve as Itô processes of the same form as the productivity indices. It will be shown in the Appendix that this is indeed the case of the equilibrium outcomes for $p(t)$ and $q(t)$. Therefore:

$$
\begin{aligned}
& \frac{d p(t)}{p(t)}=\mu_{p}(t) d t+\sigma_{p}(t) d Z_{p}(t) \\
& \frac{d q(t)}{q(t)}=\mu_{q}(t) d t+\sigma_{q}(t) d Z_{q}(t),
\end{aligned}
$$


where again $d Z_{i}(t)=\xi_{i} \sqrt{d t}$ and $\xi_{i} \sim N\left(0, s_{i}\right), i=p, q$.

The current value function for this problem is:

$$
V\left(X(t), p(t), q(t), \theta_{2}(t)\right)=\max _{\{x(s) \mid s \in[t, \infty)\}} E_{t} \int_{t}^{\infty} e^{-\alpha(s-t)} q(s)\left[p(s)-r \gamma\left(\theta_{2}(s)\right)\right] x(s) d s
$$

where the maximization is subject to $X(t),(3),(5)$ and (6), as well as to the resource constraint

$$
d X(t)=-x(t) d t, \quad X(0)=X_{0} .
$$

Notice that since the demand price $q(t)$ is taken to be the marginal utility of consumption $\left(U^{\prime}(c)\right)$, and the discount rate $\alpha$ is taken to be that of the representative consumer, this value function can be interpreted as measuring the present value of the dividend stream accruing to the representative consumer as the ultimate owner of the reserves (see Duffie, 1988, chap. 25). In maximizing this present value, the extraction firm therefore takes into account the preferences of the consumer-owner, including his attitude towards risk $\bigsqcup^{5}$ It is therefore as if the resource firm (i.e. the manager) were acting on behalf of the consumer (i.e. the owner) to maximize the present value of the dividend stream, thus resulting in a consumption-efficient outcome.

Let $V_{i}$ denote the derivative with respect to argument $i$, for $i, j=p, q, \theta_{2}$, and let $\Delta_{i}=i$. Then the Bellman equation associated to this time-autonomous problem is:

$$
\alpha V=\max _{x}\left[q[p-r \gamma] x-V_{X} x+\sum_{i} \Delta_{i} \mu_{i} V_{i}+\frac{1}{2} \sum_{i, j} \Delta_{i} \Delta_{j} \sigma_{i} \sigma_{j} V_{i j}\right] .
$$

An interior solution for $x$ will satisfy the following necessary condition:

$$
V_{X}=q(p-r \gamma)
$$

\footnotetext{
${ }^{5}$ Notice that if consumers were risk neutral, then $q(t)$ would be independent of $c(t)$ and whether the dividend stream is valued in terms of utils or in terms of the composite good would be irrelevant. That is not the case however if the consumer is risk averse, as it will be generally assumed here.
} 
Making use of $(9)$ in differentiating both sides of (8) with respect to $X$, we get

$$
\begin{aligned}
\alpha V_{X} & =-V_{X X} x+\sum_{i} \Delta_{i} \mu_{i} V_{X i}+\frac{1}{2} \sum_{i, j} \Delta_{i} \Delta_{j} \sigma_{i} \sigma_{j} V_{X i j} \\
& =\frac{1}{d t} E_{t}\left(d V_{X}\right)
\end{aligned}
$$

where the second line is obtained using Itô's lemma, $(1 / d t) E_{t}(\cdot)$ being Itô's differential operator. From (9) and (10) we therefore derive the following condition for efficient extraction of the natural resource:

$$
\frac{1}{\pi} \frac{1}{d t} E_{t}(d \pi)=\alpha
$$

where

$$
\pi=q[p-r \gamma]
$$

is the marginal profit, or net price of the resource in the ground (also called the in situ price, the asset price, or the resource rent). It is expressed in utils, as is condition (11). The condition therefore says that the discounted marginal profit from extraction, expressed in utils, must be constant over time, thus assuring indifference between extracting the marginal unit of the resource and leaving it in the ground. It can be viewed as a partial equilibrium stochastic version of Hotelling's rule.

This partial equilibrium stochastic arbitrage condition is the same as that found by Gaudet and Khadr (1991) in the case of a non durable resource. The durability property of the resource will however intervene, since, in the "general" equilibrium, $p(t)$ and $q(t)$ will depend on $Q(t)$, the above ground stock of the resource which is used as input in the production of the composite good, to which we now turn.

\section{Efficient production of the composite good}

As already noted, the production of the composite good is a function of the services of capital and the services of the above ground stock of the durable resource. We will assume that there are no costs of adjustment. The stock of capital will therefore simply be adjusted 
instantaneously to its desired level. As for the above ground stock of the resource, it is adjusted by purchasing the flow $x(t)$ extracted by the resource sector, but it is subject to depreciation at the rate $\delta$. It therefore evolves over time according to

$$
d Q(t)=[x(t)-\delta Q(t)] d t .
$$

The representative firm producing the composite good acts as a price-taker in choosing its level of capital, $K_{y}(t)$, and its rate of investment in the above stock of the resource, $x(t)$. The associated current value function, expressed in utils, is

$$
\begin{aligned}
& \Gamma\left(Q(t), p(t), q(t), \theta_{1}(t)\right)= \\
& \max _{\left\{K_{y}(s), x(s) \mid s \in[t, \infty)\right\}} E_{t} \int_{t}^{\infty} e^{-\alpha(s-t)} q(s)\left[F\left(K_{y}(s), Q(s), \theta_{1}(s)\right)-r K_{y}(s)-p(s) x(s)\right] d s,
\end{aligned}
$$

where the maximization is subject to (13), (5) and (6). For the reasons already mentioned in the previous section in the case of the resource extraction firm, this representative firm can be thought of as managing the production of the composite good on behalf of the consumerowner so as to maximize the present value of the resulting dividend stream, hence generating a consumption-efficient outcome.

The Bellman equation associated to this optimization problem is

$$
\alpha \Gamma=\max _{K_{y}, x}\left[q\left[F-r K_{y}-p x\right]+\Gamma_{Q}(x-\delta Q)+\sum_{i} \Delta_{i} \mu_{i} \Gamma_{i}+\frac{1}{2} \sum_{i, j} \Delta_{i} \Delta_{j} \sigma_{i} \sigma_{j} \Gamma_{i j}\right]
$$

for $i, j=p, q, \theta_{1}$ and $\Delta_{i}=i$. The first-order necessary conditions for the maximization of the right-hand side are

$$
\begin{gathered}
F_{K}=r \\
\Gamma_{Q}=q p .
\end{gathered}
$$

Differentiating both sides of 15 with respect to $Q$, making use of (16) and 17 and of 
Itô's lemma, we find that:

$$
\begin{aligned}
\alpha \Gamma_{Q} & =q F_{Q}-\Gamma_{Q} \delta+\Gamma_{Q Q}(x-\delta Q)+\sum_{i} \mu_{i} \Delta_{i} \Gamma_{Q i}+\frac{1}{2} \sum_{i, j} \Delta_{i} \Delta_{j} \sigma_{i} \sigma_{j} \Gamma_{Q i j} \\
& =q F_{Q}-\Gamma_{Q} \delta+\frac{1}{d t} E_{t}\left(d \Gamma_{Q}\right) .
\end{aligned}
$$

From (17) and (18) it follows that the optimal holding of the resource stock as input in the production of the composite good must satisfy

$$
\frac{F_{Q}}{p}-\delta+\frac{1}{q p} \frac{1}{d t} E_{t} d(q p)=\alpha
$$

Recall that $q p$ is the gross market price of the resource expressed in utils. The left-hand side of this arbitrage condition represents the marginal return at date $t$ from holding the stock of resource $Q(t)$ above ground: its marginal product, corrected for the rate of depreciation and for the expected capital gains to be made from holding it. Since the right-hand side is constant, so must be the left-hand side: the marginal return must be the same at each

date, leaving the owner indifferent between adding another unit to the stock above ground or leaving it in the ground to be exploited at a future date. This condition is of course specific to the fact that the resource is durable.

The efficiency conditions derived in this section and the previous one serve to determine the rates of return on assets that will be used to define the intertemporal stochastic opportunity set of the consumer. We now turn to the consumer's optimization problem.

\section{The consumer's consumption and portfolio decisions}

Consumers, as owners of the assets in the economy, decide both on how much to consume at each date and how to allocate their wealth between capital, bonds, in situ resources, and above ground resources. Those consumption and asset demands serve to generate the price signals that the producers take into account in making their own decisions.

Except for the bond, whose instantaneous rate of return $r$ is riskless, the asset returns 
can be expected to evolve as a stochastic process of the following form:

$$
d R_{i}(t)=\mu_{i}(t) d t+\sigma_{i}(t) d Z_{i}(t), \quad i=K, X, Q
$$

As in the case of the prices of the previous two sections, it will be shown in the Appendix that those stochastic processes are indeed compatible with equilibrium. As for the riskless asset, its return will be denoted

$$
d R_{B}(t)=r d t
$$

We know however that $\mu_{k}=F_{K}$ and that, from the efficiency condition (16) for the production of the composite good, one of the equilibrium conditions will be $F_{K}=r$. It follows that in equilibrium we must have $\sigma_{K}=0$. Therefore we may write

$$
d R_{K}(t)=d R_{B}(t)=d R(t)=r d t
$$

In other words, the return on the accumulated stock of the composite good must be the same at all times in both of its uses.

Denote by $\lambda(t)$ the asset price of a unit of reserves expressed in terms of the composite good. The consumers total wealth at time $t, W(t)$, will therefore be given by

$$
W(t)=K(t)+B(t)+\lambda(t) X(t)+p(t) Q(t) .
$$

The first three elements of wealth are the same as in Gaudet and Khadr (1991). Because of the durability property of the resource, a fourth element now appears, namely $Q(t)$, which is valued at the gross market price of the resource in term of the composite good, $p(t)$.

Differentiating (23) totally with respect to time we obtain the consumer's stochastic wealth constraint,

$$
d W(t)=-c(t) d t+W(t)\left[\omega_{X}(t) d R_{X}(t)+\omega_{Q}(t) d R_{Q}(t)+\left(1-\omega_{X}(t)-\omega_{Q}(t)\right) d R(t)\right]
$$


where $\omega_{X}(t)$ and $\omega_{Q}(t)$ are respectively the share of the representative consumer's wealth invested in the stock of resource below ground and above ground, and $c(t)$ is consumption.

The representative consumer's current value function is then

$$
J\left(W(t), \theta_{1}(t), \theta_{2}(t)\right)=\max _{\left\{c(s), \omega_{X}(s), \omega_{Q}(s) \mid s \in[t, \infty)\right\}} \int_{t}^{\infty} e^{-\alpha(s-t)} U(c(s)) d s,
$$

where the maximization is subject to (24), (20), and (22), as well as to the state $\left(W(t), \theta_{1}(t), \theta_{2}(t)\right)$ inherited at date $t$.

The corresponding Bellman equation is given by

$$
\begin{aligned}
\alpha J & =\max _{c, \omega_{X}, \omega_{Q}}\left[U(c)+\left\{W\left(\omega_{X} \mu_{X}+\omega_{Q} \mu_{Q}+\left(1-\omega_{X}-\omega_{Q}\right) r\right)-c\right\} J_{W}\right. \\
& \left.+\frac{1}{2} \sum_{k, l} \omega_{k} \omega_{l} \sigma_{k l} W^{2} J_{W W}+\frac{1}{2} \sum_{i} \sum_{l} \omega_{l} \Delta_{i} \sigma_{l i} W J_{W i}+\sum_{i} \Delta_{i} \mu_{i} J_{i}+\frac{1}{2} \sum_{i, j} \Delta_{i} \Delta_{j} \sigma_{i j} J_{i j}\right],
\end{aligned}
$$

for $i, j=\theta_{1}, \theta_{2}, l, k=X, Q$, and $\Delta_{i}=i$. Note that $\sigma_{X i}=\operatorname{cov}\left(d R_{X}, d \theta_{i}\right)$ and $\sigma_{Q i}=$ $\operatorname{cov}\left(d R_{Q}, d \theta_{i}\right)$.

The following conditions must hold for an interior solution for $c, \omega_{X}$, and $\omega_{Q}$ :

$$
\begin{gathered}
J_{W}=U^{\prime}(c) \\
J_{W}\left(\mu_{X}-r\right)+J_{W W} W\left(\omega_{X} \sigma_{X}^{2}+\omega_{Q} \sigma_{X Q}\right)+\sum_{i} \Delta_{i} \sigma_{X i} J_{W i}=0 \\
J_{W}\left(\mu_{Q}-r\right)+J_{W W} W\left(\omega_{Q} \sigma_{Q}^{2}+\omega_{X} \sigma_{X Q}\right)+\sum_{i} \Delta_{i} \sigma_{Q i} J_{W i}=0 .
\end{gathered}
$$

Condition (27) is the usual envelope condition, while (28) and (29) jointly relate the shares $\omega_{X}$ and $\omega_{Q}$ of the consumer's wealth held in the risky assets $X(t)$ and $Q(t)$ to their excess returns over the riskless rate, their variances and covariances. 


\section{Evolution of the asset and the flow prices of the resource}

In the case of a non-durable resource, the Hotelling rule is the sole condition that determines the evolution of the in situ value of the resource and, as a result, of the market flow price of the resource. As shown in Gaudet and Khadr (1991), this intertemporal arbitrage condition can be viewed as an equilibrium asset-pricing condition. In the case of a durable resource, the Hotelling rule must still hold, but it is not anymore the only assets market equilibrium condition, since the resource can also be held above ground as a productive asset once extracted. Those two equilibrium conditions will now simultaneously play a role in determining the evolution of the equilibrium resource price.

The two conditions have already been encountered in a partial equilibrium form as efficiency conditions (11) and (19). We will now use those two conditions along with the consumer's optimality conditions just derived to establish their interpretation as equilibrium asset-pricing rules. To do this, first differentiate both sides of the Bellman equation (26) with respect to $W$, to get

$$
\begin{aligned}
\alpha J_{W} & =\left[\left(W\left(\omega_{X} \mu_{X}+\omega_{Q} \mu_{Q}+\left(1-\omega_{X}-\omega_{Q}\right) r\right)-c\right) J_{W W}\right. \\
& +\frac{1}{2} \sum_{k, l} \omega_{k} \omega_{l} \sigma_{k l} W^{2} J_{W W W}+\sum_{i} \sum_{l} \omega_{l} \Delta_{i} \sigma_{l i} W J_{W W i} \\
& \left.+\sum_{i} \Delta_{i} \mu_{i} J_{W i}+\frac{1}{2} \sum_{i, j} \Delta_{i} \Delta_{j} \sigma_{i j} J_{W i j}\right] \\
& +\left[\left(\omega_{X} \mu_{X}+\omega_{Q} \mu_{Q}+\left(1-\omega_{X}-\omega_{Q}\right) r\right) J_{W}\right. \\
& \left.+\sum_{k, l} \omega_{k} \omega_{l} \sigma_{k l} W J_{W W}+\sum_{i} \sum_{l} \omega_{l} \Delta_{i} \sigma_{l i} J_{W i}\right]
\end{aligned}
$$

for $i, j=\theta_{1}, \theta_{2} ; l, k=X, Q$ and $\Delta_{i}=i$. Using Itô's lemma, we verify that the first three lines 
of the right-hand side are simply $(1 / d t) E_{t} d J_{W}$. Condition 30 can therefore be rewritten

$$
\begin{aligned}
\alpha J_{W} & =\frac{1}{d t} E_{t} d J_{W} \\
& +\left[\left(\omega_{X} \mu_{X}+\omega_{Q} \mu_{Q}+\left(1-\omega_{X}-\omega_{Q}\right) r\right) J_{W}+\sum_{k, l} \omega_{k} \omega_{l} \sigma_{k l} W J_{W W}+\sum_{i} \sum_{l} \omega_{l} \Delta_{i} \sigma_{l i} J_{W i}\right] \\
& =\frac{1}{d t} E_{t} d J_{W} \\
& +r J_{W} \\
& +\omega_{X} J_{W}\left(\mu_{X}-r\right)+J_{W W} W\left(\omega_{X}^{2} \sigma_{X}^{2}+\omega_{X} \omega_{Q} \sigma_{X Q}\right)+\sum_{i} \omega_{X} \Delta_{i} \sigma_{X i} J_{W i} \\
& +\omega_{Q} J_{W}\left(\mu_{Q}-r\right)+J_{W W} W\left(\omega_{Q}^{2} \sigma_{Q}^{2}+\omega_{Q} \omega_{X} \sigma_{X Q}\right)+\sum_{i} \omega_{Q} \Delta_{i} \sigma_{Q i} J_{W i}
\end{aligned}
$$

Substituting for the necessary conditions (27), (28) and 29) for an optimal consumptionportfolio choice, this reduces to

$$
\frac{1}{U^{\prime}} \frac{1}{d t} E_{t} d U^{\prime}=\alpha-r
$$

Notice next that since $q=U^{\prime}(c)$ and $\lambda=p-r \gamma$, (11) and 19p can be rewritten respectively as

$$
\frac{1}{U^{\prime} \lambda} \frac{1}{d t} E_{t} d\left(U^{\prime} \lambda\right)=\alpha
$$

and

$$
\frac{F_{Q}}{p}-\delta+\frac{1}{U^{\prime} p} \frac{1}{d t} E_{t} d\left(U^{\prime} p\right)=\alpha
$$

Using (32) to eliminate $\alpha$, we find that the asset-pricing equilibrium requires that the following two conditions be satisfied simultaneously:

$$
\frac{1}{U^{\prime} \lambda} \frac{1}{d t} E_{t} d\left(U^{\prime} \lambda\right)-\frac{1}{U^{\prime}} \frac{1}{d t} E_{t} d U^{\prime}=r
$$

and

$$
\frac{F_{Q}}{p}-\delta+\frac{1}{U^{\prime} p} \frac{1}{d t} E_{t} d\left(U^{\prime} p\right)-\frac{1}{U^{\prime}} \frac{1}{d t} E_{t} d U^{\prime}=r .
$$


Condition (35) is the equilibrium asset-pricing formulation of the stochastic Hotelling rule. It is the same as that found in Gaudet and Khadr (1991) for a non durable resource; it applies to durable as well as non-durable resources. The left-hand side measures the expected rate of return on holding the marginal unit of the resource in the ground: the rate of growth of the value of the marginal unit of in situ resource measured in utility terms, corrected for the rate of change of the marginal utility of consumption. This expected rate of return must equal the "rate of interest" $r$, which is the return that can be obtained by holding wealth in the form of the composite good instead of in the form of resources in the ground. Notice that if (and only if) the representative consumer were risk neutral, so that $U^{\prime}$ was constant, then the condition reduces to simply equating the expected rate of growth of the in situ price, $(1 / \lambda)(1 / d t) E_{t}(d \lambda)$, to the rate of interest. But in the case of risk averse consumers, this is not sufficient: account must then be taken of the rate of change in the marginal utility of consumption. Notice also that even with a non-linear utility function, if there is no uncertainty in the investment prospects, then the condition reduces to $(d \lambda / d t) / \lambda=r$, which is the usual formulation of the basic Hotelling rule in a deterministic context.

In the case of a durable resource, the Hotelling rule (35) is not sufficient to characterize the evolution of the resource price. In that case, condition (36), which is specific to durable resources, must hold simultaneously with the Hotelling rule. The condition expresses the fact that the return on the stock of the resource accumulated above ground as a productive asset must, at the margin, be equal to the return that can be obtained by accumulating the composite good instead, either in the form of capital of bond, which in equilibrium both yield the rate of return $r$. Indeed, the left-hand side of $(36)$ is the return on the marginal unit of the resource accumulated above ground: the marginal product of its services in the production of the composite good, minus the rate of depreciation of the stock, plus the expected rate of change in the resource price valued in utils, corrected for the rate of change in the marginal utility of consumption.

Notice that since the right-hand sides of (35) and (36) are the same, both left-hand sides must be equal: there must, in equilibrium, be indifference between holding the resource 
below ground or above ground.

It is useful to rewrite those conditions with the rate of change of the in situ price and the flow price expressed directly in terms of the composite good rather than in utility terms. To do this, we first use Itô's lemma to obtain

$$
\begin{aligned}
\frac{1}{U^{\prime} \lambda} \frac{1}{d t} E_{t} d\left(U^{\prime} \lambda\right)= & \frac{1}{\lambda} \frac{1}{d t} E_{t} d \lambda+\frac{U^{\prime \prime}}{U^{\prime}} \frac{1}{d t} E_{t} d c+\frac{1}{2} \frac{U^{\prime \prime \prime}}{U^{\prime}} \frac{1}{d t} E_{t}(d c)^{2}+\frac{U^{\prime \prime}}{U^{\prime} \lambda} \frac{1}{d t} E_{t}(d \lambda, d c) \\
\frac{1}{U^{\prime} p} \frac{1}{d t} E_{t} d\left(U^{\prime} p\right)= & \frac{1}{p} \frac{1}{d t} E_{t} d p+\frac{U^{\prime \prime \prime}}{U^{\prime}} \frac{1}{d t} E_{t} d c+\frac{1}{2} \frac{U^{\prime \prime \prime}}{U^{\prime}} \frac{1}{d t} E_{t}(d c)^{2}+\frac{U^{\prime \prime}}{U^{\prime} p} \frac{1}{d t} E_{t}(d p, d c) \\
& \frac{1}{U^{\prime}} \frac{1}{d t} E_{t} d U^{\prime}=\frac{U^{\prime \prime}}{U^{\prime}} \frac{1}{d t} E_{t} d c+\frac{1}{2} \frac{U^{\prime \prime \prime}}{U^{\prime}} \frac{1}{d t} E_{t}(d c)^{2} .
\end{aligned}
$$

Substituting from (37), (38) and (39) into (35) and (36), we find that

$$
\begin{gathered}
\frac{1}{\lambda} \frac{1}{d t} E_{t} d \lambda=r+A(c) \sigma_{\lambda c} \\
\frac{F_{Q}}{p}-\delta+\frac{1}{p} \frac{1}{d t} E_{t} d p=r+A(c) \sigma_{p c}
\end{gathered}
$$

where $A(c)=-U^{\prime \prime} c / U^{\prime}$ is the measure of relative risk aversion and $\sigma_{\lambda c}=(1 / d t) E_{t}(d \lambda / \lambda, d c / c)$ and $\sigma_{p c}=(1 / d t) E_{t}(d p / p, d c / c)$ are respectively the covariances of the rate of growth of consumption with the rate of growth of the in situ price and the rate of growth of the flow price of the resource (measured in terms of the composite good). Thus the assets market equilibrium requires that the expected rate of change of the in situ price, which is the expected return on the below ground reserves, $X(t)$, must be equal to the rate of interest corrected for the consumer's degree of risk aversion multiplied by the covariance between the rate of growth of the in situ price and the rate growth of consumption. Since the above ground resource is durable, it also requires that the rate of return on its stock, $Q(t)$, be equal to the same rate of interest corrected for the measure of the consumer's risk aversion multiplied by the covariance between the rate of growth of the market flow price and the rate of growth of consumption.

Notice that if $U^{\prime \prime}$ is negative, as is being assumed, the measure of relative risk aversion is 
positive, the consumer being risk averse. This means that the second term on the right-hand side of each equation will take on the sign of the relevant covariance. For instance, if $\sigma_{\lambda c}$ is positive, so that a high (low) return on holding the resource stocks in the ground tends to be associated with a high (low) rate of growth in consumption, then holding reserves in the ground is a relatively risky investment and requires a return that exceeds the riskless rate $r$. The same can be said for holding resource stocks above ground if $\sigma_{p c}$ is positive. On the other hand, if $\sigma_{\lambda c}$ is negative, then holding resources in the ground constitutes a form of insurance against adverse results concerning the growth of consumption. The rate of return on those reserves will then be lower than the riskless rate $r$. It may in fact be negative if, for any given degree of risk aversion, the covariance is sufficiently negative, or if, for any given negative covariance, the consumer is sufficiently risk averse. The same can be said of investment in above ground stocks of the resource when $\sigma_{p c}$ is negative.

The covariances $\sigma_{p c}$ and $\sigma_{\lambda c}$ are of course related. Indeed, since $p=\lambda+r \gamma$, we will have

$$
p \sigma_{p c}=\lambda \sigma_{\lambda c}+r \gamma \sigma_{\gamma c}
$$

or, written differently,

$$
\sigma_{p c}=\left(1-\frac{r \gamma}{p}\right) \sigma_{\lambda c}+\frac{r \gamma}{p} \sigma_{\gamma c}
$$

Hence $\sigma_{p c}$ is the weighted sum of $\sigma_{\lambda c}$ and $\sigma_{\gamma c}$, with the weights being respectively the share in the price $(p)$ of the rent $(\lambda)$ and of marginal extraction cost $(r \gamma)$. Thus $\sigma_{p c}$ and $\sigma_{\lambda c}$ can be of different signs only if $\sigma_{\lambda c}$ and $\sigma_{\gamma c}$ are of different signs. Furthermore, with positive extraction cost, we will have $\sigma_{p c}=\sigma_{\lambda c}$ if and only if $\sigma_{\lambda c}=\sigma_{\gamma c}$, and hence $\sigma_{p c}=\sigma_{\gamma c}$.

Eliminating $A(c)$ from (40) and (41) and using (42) and the fact that

$$
\frac{1}{\lambda} \frac{1}{d t} E_{t} d \lambda=\frac{p}{\lambda} \frac{1}{p} \frac{1}{d t} E_{t} d p-\frac{r \gamma}{\lambda} \frac{1}{\gamma} \frac{1}{d t} E_{t} d \gamma
$$


we find that

$$
\frac{1}{p} \frac{1}{d t} E_{t} d p=\frac{\lambda}{r \gamma}\left\{\left(\frac{\sigma_{p c}-\sigma_{\lambda c}}{\sigma_{\gamma c}}\right) r+\frac{\sigma_{\lambda c}}{\sigma_{\gamma c}}\left(\frac{F_{Q}}{p}-\delta\right)\right\}+\frac{\sigma_{p c}}{\sigma_{\gamma c}} \frac{1}{\gamma} \frac{1}{d t} E_{t} d \gamma
$$

which is the expression for the expected rate of change of the flow price of the resource. It is interesting to compare this expression for the expected rate of price change to its equivalent in the deterministic case, which is

$$
\frac{1}{p} \frac{d p}{d t}=\frac{\lambda}{r \gamma}\left(\frac{F_{Q}}{p}-\delta\right)+\frac{1}{\gamma} \frac{d \gamma}{d t}
$$

If and only if $\sigma_{p c}=\sigma_{\lambda c}=\sigma_{\gamma c}$ will (44) yield a somewhat similar result, with, however, the important distinction that the deterministic rates of change of price and of cost being replaced by their expected values, since the uncertainty remains. It is, however, highly unlikely that all three covariances with consumption will take the exact same value.

In the general case, the behavior of the expected price path will therefore depend critically on the relative values of the three covariances and will be highly unpredictable. To illustrate, suppose that the rate of depreciation of the above ground stock is sufficiently small so that $F_{Q}>\delta p$, and that the expected rate of growth of cost is negative (through technological progress) ${ }^{6}$ Assume also that $\sigma_{\lambda c}>0$, so that the return on holding reserves in the ground is positively correlated with the rate of change of consumption, and that the reverse is true of the rate of change of costs, so that $\sigma_{\gamma c}<0$. Note that the latter assumption implies that positive technological change in resource extraction tends to occur when the economy is performing well in terms of consumption, since $\sigma_{\gamma c}$ is negatively related to $\sigma_{2 c} \cdot 7^{7}$ Under those assumptions, it can be seen from that $\sigma_{p c}-\sigma_{\lambda c}<0$, so that both terms on the right-hand side of (44) are negative and so is the expected rate of change of the resource. If we assume instead that $\sigma_{\lambda c}<0$, so that holding resources in the ground tends to be viewed as insurance against unfavorable performances in consumption, and that $\sigma_{2 c}<0$ and hence

\footnotetext{
${ }^{6}$ Note that the reverse assumption is also plausible if there is an important depletion effect on extraction cost that dominates any effect of technological progress.

${ }^{7}$ In fact, $\sigma_{\gamma c}=\frac{\gamma^{\prime}}{\gamma} \theta_{2} \sigma_{2 c}$, and $\gamma^{\prime}<0$.
} 
$\sigma_{\gamma c}>0$, then the sign of the first term is ambiguous and so is that of the second term (since $\sigma_{p c}$ may well be negative). In such a case, the sign of the expected rate of price change cannot be determined analytically. Analytical indeterminacy will obviously persist if $\sigma_{\lambda c}$ and $\sigma_{\gamma c}$ happen to be of the same sign, whether positive or negative.

The expression in (44) for the expected rate of price change is also quite different from the one that arises when the resource is a non durable, analyzed in Gaudet and Khadr (1991), namely

$$
\frac{1}{p} \frac{1}{d t} E_{t} d p=\left(1-\frac{r \gamma}{p}\right)\left(r+A(c) \sigma_{\lambda c}\right)+\frac{r \gamma}{p} \frac{1}{\gamma} \frac{1}{d t} E_{t} d \gamma
$$

In that case the expected price change is simply a weighted average of the rate of interest adjusted for the risk aversion factor and the rate of change of the cost of extraction, where the weights are respectively the share of the rent in price and the share of costs in price. This is to be compared to the well known basic pricing equation that arises from the Hotelling rule in the deterministic case, namely

$$
\frac{1}{p} \frac{d p}{d t}=\left(1-\frac{r \gamma}{p}\right) r+\frac{r \gamma}{p} \frac{1}{\gamma} \frac{d \gamma}{d t}
$$

Thus, even in the case of a non durable resource, stochasticity in the production processes has an important impact on the equilibrium behavior of the resource price. Let us assume the rate of change of the cost of extraction to be negative. Then, in the deterministic case, the price may be declining at first since the second term may dominate the first one for low levels of rent, but it must eventually be increasing as the share of the rent in the price increases and that of cost decreases. Thus the resource price path will be either continuously increasing or be U-shaped, and therefore will necessarily end up increasing. Things are different in the stochastic case. Indeed, if $\sigma_{\lambda c}$ is negative, which means that favorable returns on the in situ resource stock tend to be associated to unfavorable performances of the economy (as captured by the growth in consumption), then the return expected from holding the resource stock in the ground will be smaller than the rate of interest, since holding the resource stock then appears as a form of insurance against bad prospects for consumption. In fact there is 
nothing to prevent the first term from being negative, since $r+A(c) \sigma_{\lambda c}$ may well be negative if $A(c) \sigma_{\lambda c}$ is sufficiently large, in which case, if the expected rate of change of extraction cost is also negative, the expected rate of change in the price will be negative independently of the share of the rent in the price. As is clear from (44), the durability of the resource further highlights the need to take into account uncertainty when attempting to characterize empirically the evolution of resource prices.

Note finally that since, by definition, $\mu_{X}=(1 / \lambda)(1 / d t) E_{t} d \lambda$ and $\mu_{Q}=\left(F_{Q} / p\right)-\delta+$ $(1 / p)(1 / d t) E_{t} d p$, respectively the expected rates of return on holding resource stocks respectively below ground and above ground, then from (40) and (41) we have that the expected instantaneous excess returns on holding those assets are written

$$
\mu_{X}-r=A(c) \sigma_{\lambda c}
$$

and

$$
\mu_{Q}-r=A(c) \sigma_{p c}
$$

Furthermore, if there exists a reference market portfolio (denote it $M$ ) with the property that $\sigma_{M c} \neq 0$, then we will also have $\mu_{M}-r=A(c) \sigma_{M c}$. By substitution into (48) and (49) we then get

$$
\mu_{X}-r=\beta_{X}\left(\mu_{M}-r\right)
$$

and

$$
\mu_{Q}-r=\beta_{Q}\left(\mu_{M}-r\right)
$$

where $\beta_{i}=\sigma_{i c} / \sigma_{M c}, i=\lambda, p$ are the well known "beta-coefficients". A positive $\beta_{i}$ implies that holding the resource in question constitutes a relatively risky investment, whereas the reverse is true if it is negative. Such specifications suggest that an asset pricing formulation of the nonrenewable resource exploitation problem can offer an interesting approach to estimating the temporal behavior of resource prices. 8

\footnotetext{
${ }^{8}$ There have been a few attempts, based at least in part on Gaudet and Khadr (1991), at using such an approach to estimate the Hotelling rule for non durable resources or, if durable, by treating it implicitly
} 


\section{Conclusion}

The Hotelling rule is best viewed as an equilibrium condition in the assets market rather than simply an equilibrium condition in the flow market, as it very often is. Assets market equilibrium requires that holding a unit of the resource yield no more and no less than extracting it in order to invest in some other asset, thus irreversibly depleting the resource stock. Establishing the intertemporal assets market equilibrium in such a context requires that careful thought be given to what enters the return on holding the resource stock. As mentioned at the outset, there are a number of real world factors that make this task more complicated than it appears from the seminal paper of Hotelling, where the return could only be the capital gains it generates by holding it in the ground. As was shown in Gaudet and Khadr (1991) for non durable resources, not the least of those factors is uncertainty about future investment prospects. If in addition the resource is durable, depleting the in situ resource stock creates an above ground asset which, contrary to the in situ stock, yields a dividend in the form of productive services. This paper has shown that caution should be used in drawing analytical predictions about resource pricing behavior in the context of durable resources and stochastic investment opportunities. It is certainly too simplistic to imply from the most basic formulation of the Hotelling rule that the net price of the resource should be growing at the rate of interest, and it should be no surprise that observed resource prices do not behave in such a fashion. Our results highlight the importance for empirical studies of resource prices of taking account uncertainty about future investment prospects, and especially so in the case of durable resources. Of course, other factors, such as depletion effects on extraction costs and the structure of the resource markets are also very important in explaining the departure of the observed price behavior from the simple $r \%$ rule.

as non durable. See in particular Slade and Thille (1997) and Young and Ryan (1996), and more recently Kakeu (2010) who makes use of stock market data and financial econometric methods to estimate the beta coefficient for oil and gas. Empirical studies of resource price behavior that explicitly take into account the durability of the resource are to our knowledge still nonexistent. 


\section{Appendix}

\section{Characterization of the equilibrium prices and returns}

The demand prices and asset returns have been taken to be those that equilibrate the markets when extraction, production and consumption take place simultaneously. They have furthermore been assumed to evolve in equilibrium as stochastic processes, given that the exogenous productivity indices evolve stochastically. In this Appendix we show that such assumptions are indeed compatible with the equilibrium and illustrate how the respective equilibrium drifts and variances can be calculated as functions of the primitives.

It has already been argued in the last section that we must have in equilibrium $d R_{K}(t)=$ $d R_{B}(t)=r d t$. There remains to characterize the prices $p(t)$ and $q(t)$, and the returns $d R_{X}(t)$ and $d R_{Q}(t)$. Each of those prices and returns will at any given date be a function of the state of the economy, which is given by the vector $\left(K(t)+B(t), X(t), Q(t), \theta_{1}(t), \theta_{2}(t)\right)$.

Consider first the utility price of the composite good. It is given by $q=U^{\prime}(c)$. If we replace the decision variable $c(t)$ by its equilibrium value, then $q(t)$ can be expressed as

$$
q(t)=\mathbf{Q}\left(K(t)+B(t), X(t), Q(t), \theta_{1}(t), \theta_{2}(t)\right) .
$$

Similarly, we know from condition (17) that $q(t) p(t)=\Gamma_{Q}\left(Q(t), p(t), q(t), \theta_{1}(t)\right)$. Substituting for the utility price $q(t)$ from $(52)$, we see that the implicit solution for $p(t)$ will take the form

$$
p(t)=\mathbf{P}\left(K(t)+B(t), X(t), Q(t), \theta_{1}(t), \theta_{2}(t)\right) .
$$

As for the asset price (in situ price) of the resource, $\lambda(t)$, it is given by $\lambda(t)=p(t)-r \gamma\left(\theta_{2}\right)$, namely the gross market price of a unit or the resource minus the cost of taking it out of the ground, expressed in terms of the composite good. Hence, substituting for $p(t)$ from (53), 
the equilibrium value of $\lambda(t)$ can be written

$$
\begin{aligned}
\lambda(t) & =\Lambda\left(K(t)+B(t), X(t), Q(t), \theta_{1}(t), \theta_{2}(t)\right) \\
& =\mathbf{P}\left(K(t)+B(t), X(t), Q(t), \theta_{1}(t), \theta_{2}(t)\right)-r \gamma\left(\theta_{2}(t)\right) .
\end{aligned}
$$

Given that the productivity indices $\theta_{1}$ and $\theta_{2}$ evolve as Itô processes, then, as assumed in (6), (5) and (20), so will the equilibrium values of $p, q, d R_{X}$ and $d R_{Q}$. To verify this, consider the case of the equilibrium gross price $p$. Denote by $k$ and $b$ the instantaneous rates of change of $K$ and $B$ respectively, so that $d K=k d t$ and $d B=b d t$, and recall that $d X=-x d t$ and $d Q=x-\delta Q$. Then, using Itô's lemma, we get that

$$
\begin{aligned}
d p & =\mathbf{P}_{K+B}(k+b)-\mathbf{P}_{X} x+\mathbf{P}_{Q}(x-\delta Q) \\
& +\mathbf{P}_{\theta_{1}} d \theta_{1}+\mathbf{P}_{\theta_{2}} d \theta_{2}+\mathbf{P}_{\theta_{1} \theta_{2}}+\frac{1}{2} \mathbf{P}_{\theta_{1} \theta_{1}}\left(d \theta_{1}\right)^{2}+\frac{1}{2} \mathbf{P}_{\theta_{2} \theta_{2}}\left(d \theta_{2}\right)^{2}
\end{aligned}
$$

Substituting for $d \theta_{1}$ and $d \theta_{2}$ from (3), we get

$$
\begin{aligned}
\frac{d p}{p} & =\left[\frac{\mathbf{P}_{K+B}}{\mathbf{P}}-\frac{\mathbf{P}_{X}}{\mathbf{P}} x+\frac{\mathbf{P}_{Q}}{\mathbf{P}}(x-\delta Q)+\frac{\mathbf{P}_{\theta_{1}}}{\mathbf{P}} \mu_{1}+\frac{\mathbf{P}_{\theta_{2}}}{\mathbf{P}} \mu_{2}+\frac{\mathbf{P}_{\theta_{1} \theta_{2}}}{\mathbf{P}} \sigma_{1} \sigma_{2} \xi_{1} \xi_{2}\right. \\
& \left.+\frac{1}{2}\left(\frac{\mathbf{P}_{\theta_{1} \theta_{1}}}{\mathbf{P}} \sigma_{1}^{2} \xi_{1}^{2}+\frac{\mathbf{P}_{\theta_{2} \theta_{2}}}{\mathbf{P}} \sigma_{2}^{2} \xi_{2}^{2}\right)\right] d t \\
& +\left[\frac{\mathbf{P}_{\theta_{1}}}{\mathbf{P}} \sigma_{1} \xi_{1}+\frac{\mathbf{P}_{\theta_{2}}}{\mathbf{P}} \sigma_{2} \xi_{2}\right] \sqrt{ } d t
\end{aligned}
$$

which yields (5) as assumed, where

$$
\begin{gathered}
\mu_{p}=\frac{\mathbf{P}_{K+B}}{\mathbf{P}}-\frac{\mathbf{P}_{X}}{\mathbf{P}} x+\frac{\mathbf{P}_{Q}}{\mathbf{P}}(x-\delta Q)+\frac{\mathbf{P}_{\theta_{1}}}{\mathbf{P}} \mu_{1}+\frac{\mathbf{P}_{\theta_{2}}}{\mathbf{P}} \mu_{2}+\frac{\mathbf{P}_{\theta_{1} \theta_{2}}}{\mathbf{P}} \sigma_{1} \sigma_{2} \xi_{1} \xi_{2} \\
+\frac{1}{2}\left(\frac{\mathbf{P}_{\theta_{1} \theta_{1}}}{\mathbf{P}} \sigma_{1}^{2} \xi_{1}^{2}+\frac{\mathbf{P}_{\theta_{2} \theta_{2}}}{\mathbf{P}} \sigma_{2}^{2} \xi_{2}^{2}\right) \\
=\frac{1}{\mathbf{P}(\cdot)} \frac{1}{d t} E_{t}(d \mathbf{P}(\cdot)) \\
\sigma_{p}=\frac{\left[\frac{\mathbf{P}_{\theta_{1}}}{\mathbf{P}} \sigma_{1} \xi_{1}+\frac{\mathbf{P}_{\theta_{2}}}{\mathbf{P}} \sigma_{2} \xi_{2}\right]}{\xi_{2}}=\left(\frac{1}{d t} \operatorname{var}\left(\frac{d \mathbf{P}(\cdot)}{\mathbf{P}(\cdot)}\right)\right)^{\frac{1}{2}}
\end{gathered}
$$


and

$$
\xi_{p}=\xi_{2}
$$

Using Itô's lemma we can derive in the same way $\mu_{q}=(1 / \mathbf{Q}(\cdot))(1 / d t) E_{t}(d \mathbf{Q}(\cdot))$ and $\sigma_{q}=$ $\left((1 / d t) \operatorname{var} E_{t}(d \mathbf{Q}(\cdot) / \mathbf{Q}(\cdot))^{\frac{1}{2}}\right.$, as well as $\mu_{\lambda}=(1 / \Lambda(\cdot))(1 / d t) E_{t}(d \Lambda(\cdot))$ and $\sigma_{\lambda}=\left((1 / d t) \operatorname{var} E_{t}(d \Lambda(\cdot) / \Lambda(\cdot))^{\frac{1}{2}}\right.$. As for the rates of returns on $X$ and on $Q$, given by

$$
d R_{X}=\frac{d \lambda}{\lambda} \quad \text { and } \quad d R_{Q}=\left(\frac{F_{Q}}{p}-\delta\right) d t+\frac{d p}{p}
$$

their equilibrium drifts, $\mu_{X}$ and $\mu_{Q}$, and volatility, $\sigma_{X}$ and $\sigma_{Q}$, can be obtained using the above, hence verifying the appropriateness of the assumption made in 20 . 


\section{References}

Duffie, Darell (1988) Securities Markets: Stochastic Models (New York: Academic Press)

Gaudet, Gérard (2007) 'Natural Resource Economics under the Rule of Hotelling.' Canadian Journal of Economics 40, 1033-1059

Gaudet, Gérard, and Ali Khadr (1991) 'The evolution of natural resource prices under stochastic investment opportunities: An intertemporal asset-pricing approach.' International Economic Review 32, 441-455

Hotelling, Harold (1931) 'The economics of exhaustible resources.' Journal of Political Economy $39,137-175$

Kakeu, Johnson (2010) 'Estimation of the Hotelling rule for oil and for coal under stochastic investment opportunities.' Typescript, Université de Montréal

Levhari, David, and Robert Pindyck (1981) 'The pricing of durable exhaustible resources.' Quartely Journal of Economics 96, 365-378

Livernois, John (2009) 'On the Empirical Significance of the Hotelling Rule.' Review of Environmental Economics and Policy 3, 22-41

Slade, Margaret, and Henry Thille (1997) 'Hotelling Confronts CAPM: A Test of the Theory of Exhaustible Resources.' Canadian Journal of Economics 30, 685-708

_ (2009) 'Whither Hotelling: Tests of the Theory of Exhaustible Resources.' Annual Review of Resource Economics 1, 239-260

Young, Denise, and David Ryan (1996) 'Empirical testing of a risk-adjusted Hotelling model.' Ressources Energy Economics 18, 265-289 